\title{
Improving Atmospheric Plasma Spraying of Zirconate Thermal Barrier Coatings Based on Particle Diagnostics
}

\author{
Georg Mauer, Doris Sebold, Robert Vaßen, and Detlev Stöver
}

(Submitted September 12, 2011; in revised form November 3, 2011)

\begin{abstract}
Lanthanum zirconate $\left(\mathrm{La}_{2} \mathrm{Zr}_{2} \mathrm{O}_{7}\right)$ has been proposed as a promising material for thermal barrier coatings. During atmospheric plasma spraying (APS) of $\mathrm{La}_{2} \mathrm{Zr}_{2} \mathrm{O}_{7}$ a considerable amount of $\mathrm{La}_{2} \mathrm{O}_{3}$ can evaporate in the plasma flame, resulting in a non-stoichiometric coating. As indicated in the phase diagram of the $\mathrm{La}_{2} \mathrm{O}_{3}-\mathrm{ZrO}_{2}$ system, in the composition range of pyrochlore structure, the stoichiometric $\mathrm{La}_{2} \mathrm{Zr}_{2} \mathrm{O}_{7}$ has the highest melting point and other compositions are eutectic. APS experiments were performed with a TriplexPro ${ }^{\mathrm{TM}}-200$ plasma torch at different power levels to achieve different degrees of evaporation and thus stoichiometry. For comparison, some investigations on gadolinium zirconate $\left(\mathrm{Gd}_{2} \mathrm{Zr}_{2} \mathrm{O}_{7}\right)$ were included, which is less prone to evaporation and formation of non-stoichiometry. Particle temperature distributions were measured by the DPV-2000 diagnostic system. In these distributions, characteristic peaks were detected at specific torch input powers indicating evaporation and solidification processes. Based on this, process parameters can be defined to provide stoichiometric coatings that show good thermal cycling performance.
\end{abstract}

Keywords atmospheric plasma spraying, gadolinium zirconate, lanthanum zirconate, particle diagnostics, thermal barrier coating

\section{Introduction}

Thermal barrier coatings (TBCs) are key elements in the design of advanced gas turbines for both aircraft engines and land-based power generation. They make it possible to achieve the increased gas inlet temperatures required to meet growing demands on improved fuel efficiency, lower emissions, and higher thrust and power (Ref 1). TBC systems consist typically of two layers: a bond coat layer and an insulative ceramic topcoat. The bond coat is often a MCrAlY alloy $(\mathrm{M}=\mathrm{Co}, \mathrm{Ni})$ and has two major functions. It improves the bonding between the substrate and the topcoat, and it protects the substrate from corrosion and oxidation. The ceramic topcoat

This article is an invited paper selected from presentations at the 2011 International Thermal Spray Conference and has been expanded from the original presentation. It is simultaneously published in Thermal Spray 2011: Proceedings of the International Thermal Spray Conference, Hamburg, Germany, September 2729, 2011, Basil R. Marple, Arvind Agarwal, Margaret M. Hyland, Yuk-Chiu Lau, Chang-Jiu Li, Rogerio S. Lima, and André McDonald, Ed., ASM International, Materials Park, OH, 2011.

Georg Mauer, Doris Sebold, Robert Vaßen, and Detlev Stöver, Institut für Energie- und Klimaforschung (IEK-1), Forschungszentrum Jülich $\mathrm{GmbH}$, Jülich, Germany. Contact e-mail: g.mauer@fz-juelich.de. provides heat insulation due to its low thermal conductivity resulting from its bulk material characteristics as well as from microstructural features such as pores and voids (Ref 2 ).

At the end of the 1970s, zirconia stabilized by $6-8 \mathrm{wt} \%$ yttria (YSZ) was established as an almost ideal ceramic topcoat material (Ref 3) because of its high fracture toughness and thermal expansion coefficient. It is deposited by either electron beam physical vapor deposition (EB-PVD) or by atmospheric plasma spraying (APS). YSZ does not form the equilibrium phase (monoclinic and cubic zirconia) during either of the deposition processes but rather a metastable $t^{\prime}$-phase due to rapid cooling. It does not significantly transform to the equilibrium phases even at longer operating times and temperatures up to $1200{ }^{\circ} \mathrm{C}$. However, above this temperature limit the material undergoes undesirable diffusion-induced decomposition into high yttria and low yttria phases (Ref 4). While the first of these transforms on cooling to the cubic phase with low toughness, the latter converts to the monoclinic phase which is accompanied by a considerable volume change leading to strains and cracks. Furthermore, above $1200{ }^{\circ} \mathrm{C}$ significant sintering occurs, which causes an increase of the Young's modulus affecting the strain tolerance and hence reducing the thermal cycling lifetime (Ref 5,6).

These shortcomings regarding such elevated turbine gas inlet temperatures have initiated many research activities seeking even better ceramics than YSZ (Ref 79). Apart from perovskites, also hexaaluminates, doped zirconia, and ceramics with pyrochlore structure offer very attractive characteristics. In particular, several zirconate pyrochlores show low thermal conductivities as well as high thermal stabilities. Among them, lanthanum zirconate 
$\mathrm{La}_{2} \mathrm{Zr}_{2} \mathrm{O}_{7}(\mathrm{LZ})$ is phase stable to its melting point as it can largely tolerate vacancies at the $\mathrm{La}^{3+}, \mathrm{Zr}^{4+}$, and $\mathrm{O}^{2-}$ sites. At the same time, it displays a lower thermal conductivity (1.56 $\mathrm{W} \mathrm{m}^{-1} \mathrm{~K}^{-1}$, bulk material) and a lower sintering tendency when compared to YSZ. However, the thermal expansion coefficient of $9.1 \times 10^{-6} \mathrm{~K}^{-1}\left(30-1000^{\circ} \mathrm{C}\right)$ (Ref 7 ) is low in relation to bond coats and Ni-base alloy substrates $\left(\sim 15 \times 10^{-6} \mathrm{~K}^{-1}\right)$ and the toughness is poor (Ref 10). The thermal expansion coefficient may be raised by replacing lanthanum by other trivalent rare earth elements having similar ionic radii. This can also lower the thermal conductivity (Ref 11 ) or even offer the option of temperature sensing by luminescence (Ref 12). However, the problem of low fracture toughness remains crucial. For this reason, pyrochlores are applied in combination with YSZ in double-layer TBC systems (Ref 13, 14). Graded coating systems were also investigated (Ref 15). YSZ is applied as the first ceramic layer since TBC failure is often initiated by cracks occurring close to the bond coat. This YSZ interlayer can, furthermore, prevent possible reactions between the pyrochlore and the alumina-based scale (thermally grown oxide, TGO) formed on the bond coat under thermal load (Ref 16). Here, $\mathrm{LaAlO}_{3}$ was formed above $1200{ }^{\circ} \mathrm{C}$. In contrast, no significant chemical reaction was observed at YSZ LZ interfaces after thermal cycling.

The $\mathrm{La}_{2} \mathrm{O}_{3} \cdot \mathrm{ZrO}_{2}$ phase diagram shows a stable pyrochlore region up to the melting temperature of $2280{ }^{\circ} \mathrm{C}$ (Ref 17). In more recent work a melting point of $2295 \pm 10^{\circ} \mathrm{C}$ is given (Ref 18). According to the same reference, the stability region ranges from approximately 33 to $35 \mathrm{~mol} \% \mathrm{La}_{2} \mathrm{O}_{3}$ at $1500{ }^{\circ} \mathrm{C}$ ( $\mathrm{La} / \mathrm{Zr}$ atomic ratio $0.99-$ 1.08). Below the melting temperature, no fluorite phase occurs which is less ordered than the pyrochlore phase. Due to the high fusion enthalpy of $\sim 350 \mathrm{~kJ} \mathrm{~mol}^{-1}$, solidification starts directly in the form of pyrochlore. However, considerable amounts of metastable fluorite phase are formed in the case of rapid solidification, which is typical of plasma spray conditions. Such fluorite phase is transformed to pyrochlore at temperatures above $1000{ }^{\circ} \mathrm{C}$ ( Ref 19, 20). This is not critical as such transformation is not associated with significant volume change.

The processing of LZ by APS is challenging because $\mathrm{La}_{2} \mathrm{O}_{3}$ is prone to evaporate in the plasma plume resulting in non-stoichiometric coatings (Ref 16). This might be detrimental for TBC performance as thermophysical properties are affected (Ref 21). Similar problems are known from LZ EB-PVD coatings ( Ref 22). $\mathrm{La}_{2} \mathrm{O}_{3}$ shows considerably higher vapor pressure when compared to $\mathrm{ZrO}_{2}$ (Ref 23). Although reference data from the literature are not in good agreement, it is evident that the vapor pressure of lanthania is at least one magnitude higher than that of zirconia. Also evaporation rates of $\mathrm{La}_{2} \mathrm{O}_{3}$ were found to be considerably higher in the temperature range between 2250 and $2500{ }^{\circ} \mathrm{C}(\operatorname{Ref} 24)$. Evaporation products are $\mathrm{LaO}, \mathrm{O}$ and $\mathrm{O}_{2}(\operatorname{Ref} 25)$.

Cao et al. (Ref 16) attempted to prevent such nonstoichiometries by adjusting specific excess of $\mathrm{La}_{2} \mathrm{O}_{3}$ in the powder. It was concluded that the highest La content in the coating is obtained by applying a feedstock with a
$\mathrm{La} / \mathrm{Zr}$ atomic ratio between 1.0 and 1.05 . Both at smaller and also larger ratios, less La was detected in the coatings. The reason for this was assumed to be that the evaporation temperature decreases at $\mathrm{La}_{2} \mathrm{O}_{3}$ contents below and above the compositional existence range of the pyrochlore phase in the same manner as the liquidus line decreases when it approaches the eutectic compositions immediately adjacent on the left and right of this pyrochlore peak. However, no reliable reference data is available on the way in which the evaporation temperature is dependent on the $\mathrm{La}_{2} \mathrm{O}_{3}$ content.

In the present work, APS experiments were performed with a TriplexPro ${ }^{\mathrm{TM}}-200$ plasma torch at different power levels to adjust different degrees of evaporation and thus stoichiometry. The results were verified by chemical, phase, and crystallographic analyses. Although LZ was the focus of this work, some investigations with $\mathrm{Gd}_{2} \mathrm{Zr}_{2} \mathrm{O}_{7}$ (GZ) were also performed for comparison since GZ does not show such a strong tendency to evaporate the rare earth constituent.

Particle temperature distributions were measured in flight by the DPV-2000 diagnostic system. In these distributions, characteristic peaks were detected indicating evaporation and solidification processes. Based on these, as well as on chemical and crystallographic analyses, process parameters can be defined to provide stoichiometric coatings displaying good thermal cycling performance.

\section{Experimental}

The samples used in this study were coated by APS in a Multicoat facility (Sulzer Metco, Wohlen, Switzerland) with a TriplexPro ${ }^{\mathrm{TM}}$ gun mounted on a six-axis robot. The $9 \mathrm{~mm}$ diameter nozzle was used with a $1.8 \mathrm{~mm}$ diameter feedstock injector. The plasma gas composition was 46 standard liters per minute (slpm) Ar and 4 slpm He. The current was varied between 200 and 525 A yielding plasma torch input powers between 15 and $51 \mathrm{~kW}$. Particle in-flight diagnostics were performed by the DPV-2000 system (TECNAR Automation Ltd., St. Bruno, QC, Canada), which enables particle velocities, temperatures, and diameters to be measured in flight. The operating principles are described elsewhere (Ref 26).

The feedstock was a commercially available LZ powder (Praxair LAO-109, $d_{10}=7 \mu \mathrm{m}, d_{50}=44 \mu \mathrm{m}, d_{90}=80 \mu \mathrm{m}$ ) exhibiting a spherical morphology. The powder feed rate was $3.5 \mathrm{~g} \mathrm{~min}^{-1}$ and the carrier gas flow $2.0 \mathrm{slpm} \mathrm{Ar}$. The spray distance was $90 \mathrm{~mm}$ and the robot speed $500 \mathrm{~mm} \mathrm{~s}^{-1}$. The same parameters were applied to process two GZ powders. One was commercially available (Praxair GDO-103, $d_{10}=25 \mu \mathrm{m}, d_{50}=42 \mu \mathrm{m}, d_{90}=72 \mu \mathrm{m}$ ) with a spherical morphology; the other one was a fused and crushed $(\mathrm{f}+\mathrm{c})$ experimental powder $\left(d_{10}=11 \mu \mathrm{m}\right.$, $\left.d_{50}=18 \mu \mathrm{m}, d_{90}=33 \mu \mathrm{m}\right)$.

Coatings were sprayed on graphite substrates and subsequently stripped by grinding. Parts of the freestanding coatings were used for chemical analysis by 
optical emission spectroscopy with inductively coupled plasma (ICP-OES).

The remaining samples were investigated by $\mathrm{x}$-ray diffraction analysis (XRD) and then embedded into epoxy resin to prepare metallographic polished cross sections for microscopic investigation and elemental analysis. XRD was performed on a D4 ENDEAVOR diffractometer (Bruker AXS GmbH, Karlsruhe, Germany) and scanning electron microscope investigation (SEM) on an Ultra55 model (Carl Zeiss NTS GmbH, Oberkochen, Germany) combined with an energy-dispersive x-ray INCAEnergy355 spectrometer (EDS, Oxford Instruments Ltd., Abingdon, Oxfordshire, UK). For SEM examination, the samples were coated with approximately $2 \mathrm{~nm}$ platinum. EDS point analysis was performed on LZ samples with an acceleration voltage of $15 \mathrm{kV}$. Instead of the reference patterns of the EDS system internal database, a polished cross section of LZ feedstock particles was analyzed and defined as standard. The composition of this powder was confirmed by chemical analysis to be almost stoichiometric.

\section{Results and Discussion}

\subsection{Deposition Rate and Chemical Composition}

The development of the area-related LZ coating weight for the variation of torch input power between 15 and $51 \mathrm{~kW}$ displays a maximum at $21 \mathrm{~kW}$ followed by a reduction at higher power (see Fig. 1). This deterioration of the LZ deposition rate (up to $\sim 22 \mathrm{wt}$. \% when related to the maximum) can be explained in part by the evaporation of lanthania (up to 13 wt. \%, see below). The other part is assumed to be caused by decreasing deposition efficiency due to splat fragmentation and bouncing. During the spraying of GZ $(f+c)$, a similar development is observed, however at a higher level because of the different powder morphology. At $51 \mathrm{~kW}$ the deposition rate drops for 9 wt. \% relative to the maximum; 3 wt. $\%$ of which is due to the gadolinia evaporation (see below).

Chemical analysis yields an almost stoichiometric composition of the $\mathrm{LZ}$ powder feedstock (33.3 mol\%

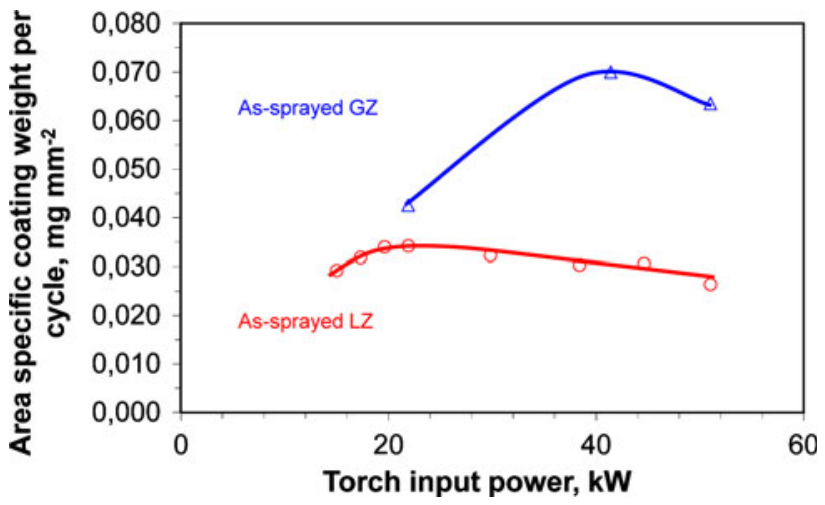

Fig. 1 Area-specific LZ and GZ ( $\mathrm{f}+\mathrm{c}$ powder) coating weight vs. torch input power between 15 and $51 \mathrm{~kW}$
$\mathrm{La}_{2} \mathrm{O}_{3}$, the $\mathrm{La} / \mathrm{Zr}$ atomic ratio is nearly 1.0). Moreover, impurities of $0.7 \mathrm{~mol} \% \mathrm{HfO}_{2}, 0.1 \mathrm{~mol} \% \mathrm{CaO}$, and $0.1 \mathrm{~mol} \% \mathrm{SiO}_{2}$ were determined. The GZ powders show moderate gadolinium excess $(\mathrm{Gd} / \mathrm{Zr}$ ratio is 1.07 and 1.11, respectively).

The lanthania content in the sprayed LZ coatings already exhibits a small initial drop at low torch input power down to $32.9 \mathrm{~mol} \%(\mathrm{La} / \mathrm{Zr}$ atomic ratio of 0.99$)$ and if the power is raised it continues to decrease to $27.0 \mathrm{~mol} \%$ at 51 $\mathrm{kW}$ corresponding to a $\mathrm{La} / \mathrm{Zr}$ atomic ratio of 0.75 (Fig. 2). Here, up to $24.8 \%$ of the lanthanum content in the powder feedstock was lost. At the same torch input power, the GZ coatings show a gadolinia content of $30.5 \mathrm{~mol} \%$ corresponding to a $\mathrm{Gd} / \mathrm{Zr}$ ratio of 0.89 . This means that, relative to the feedstock, $16.8 \%$ of the gadolinium was lost. As expected because of the lower vapor pressure of gadolinia, this is less than for LZ. The evaporation of lanthania was confirmed by optical emission spectroscopy revealing strong $\mathrm{La}$ and $\mathrm{La}^{+}$emission lines in the plasma plume radiation (not shown in this paper).

The La evaporation is in good agreement with the figure of $26 \%$ found by Chen et al. in their plasma-sprayed LZ coatings (Ref 21). Based on their reported process conditions, a torch input power of $50 \mathrm{~kW}$ can be estimated. Cao et al. (Ref 16) reported a maximum La loss of $13 \%$ relative to the content in the feedstock, but at a lower torch input power of $21 \mathrm{~kW}$.

\subsection{Phase Composition}

XRD analysis of the LZ and GZ feedstock powders yielded solely pyrochlore phases. In the LZ coatings, the content of defective fluorite phase grows as the torch input power is raised. Figure 3 shows x-ray diffractograms of two as-sprayed coatings for low and high torch power. With increasing torch input power, the XRD peaks shift to larger $2 \theta$ values indicating the increasing non-stoichiometry. Moreover, the peaks are broadened because of the locally varying stoichiometry. Results of quantitative phase analysis are given in Fig. 4. As the Rietveld analysis (Ref 27) applied for this is based mainly on the weak pyrochlore superlattice reflexes, the absolute results may be subject to errors which are difficult to estimate. However, the trend

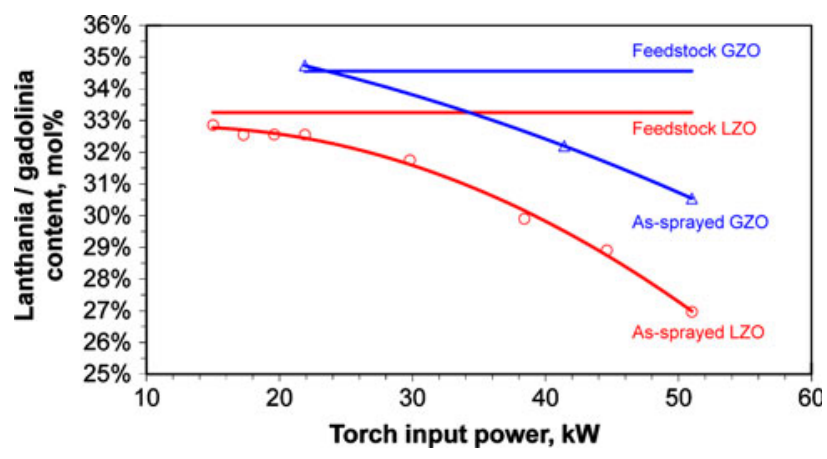

Fig. 2 Lanthania and gadolinia $(\mathrm{f}+\mathrm{c}$ powder $)$ contents determined by chemical analysis vs. torch input power between 15 and $51 \mathrm{~kW}$ 


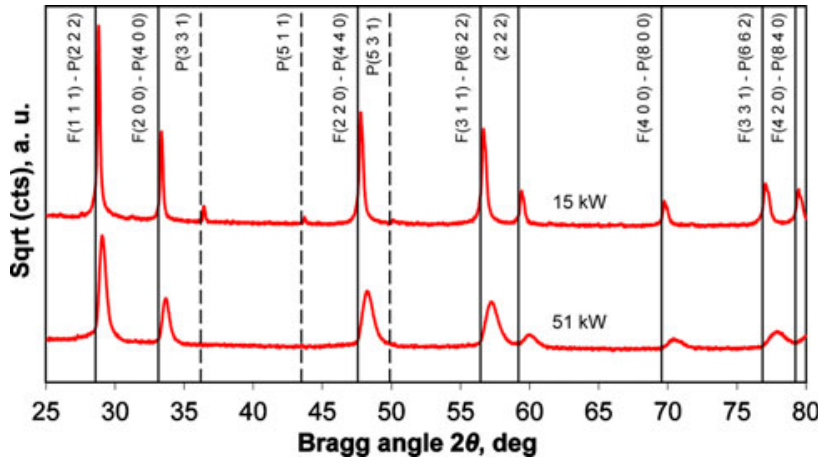

Fig. 3 X-ray diffractograms of two as-sprayed coatings for low and high torch input power

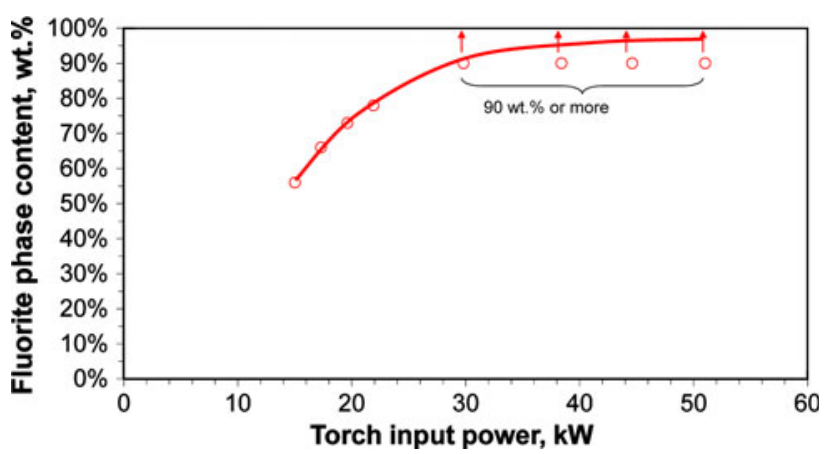

Fig. 4 Fluorite phase content in the as-sprayed LZ coatings determined by XRD vs. torch input power between 15 and $51 \mathrm{~kW}$

was evident and consistent. At $30 \mathrm{~kW}$ and above, the fluorite phase content is $90 \mathrm{wt}$ \% or more, which cannot be differentiated more exactly. In each case, the balance is pyrochlore phase. In the range of XRD detectability, no impurity phases were identified. Obviously, the formation of defective fluorite phase, which is less ordered than the pyrochlore phase, is an effect of the rapid cooling upon impingement on the substrate of such material fractions which are still molten at that time. In contrast, the material fractions which have already solidified during flight may be deposited as pyrochlore.

The GZ coatings show solely defective fluorite phase. According to the phase diagram, solidification starts as fluorite phase. With further cooling, the formation of pyrochlore below approximately $1530{ }^{\circ} \mathrm{C}$ is suppressed due to the high cooling rate at deposition on the substrate. Probably, such low temperatures are not reached by any particles still in flight so that pyrochlore phase cannot be formed then.

The Rietveld refinement of the XRD results shows that the lattice parameter of the LZ and GZ fluorite phase decreases with rising torch input power (Fig. 5). The reason for this is the changing stoichiometry due to the evaporation of lanthania and gadolinia. As this varies locally in the coatings (see below), the XRD peaks are increasingly broadened.

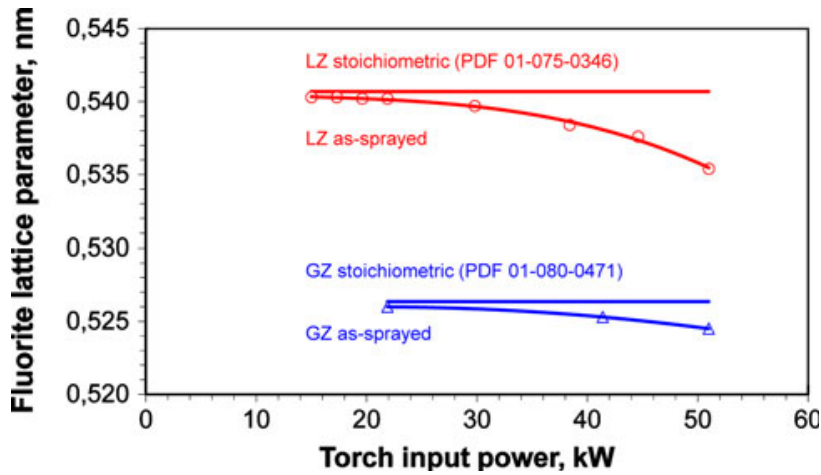

Fig. $5 \mathrm{LZ}$ and GZ (f+c powder) fluorite phase lattice parameter determined by Rietveld refinement vs. torch input power between 15 and $51 \mathrm{~kW}$

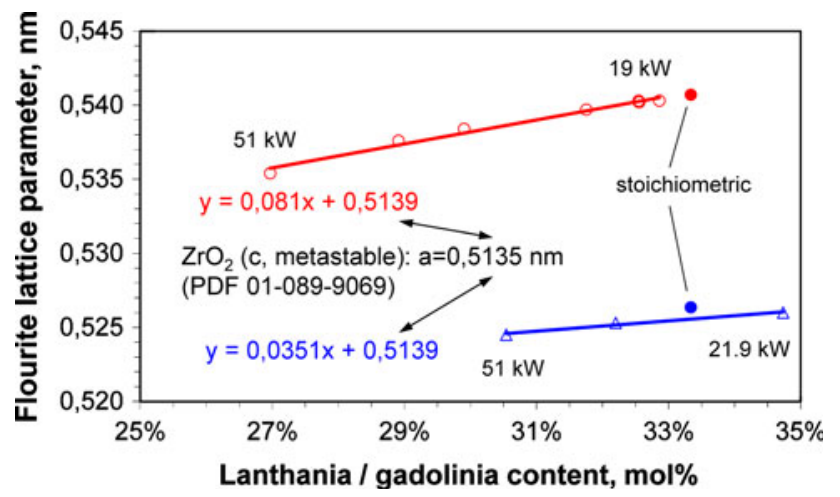

Fig. 6 Correlation of the LZ and GZ (f $+c$ powder) fluorite phase lattice parameters to the rare earth oxide contents vs. torch input power between 15 and $51 \mathrm{~kW}$

The strong correlation according to Vegard's law (Ref 28) becomes evident if the fluorite lattice parameters are plotted versus the lanthania and gadolinia contents (Fig. 6). The linear equation of the regression lines shows intersections with the vertical axis at zero rare earth content close to the dimensions of the unit cell of metastable cubic zirconia, also with fluorite structure. Evidently, with increasing evaporation more rare earth sites are occupied by $\mathrm{Zr}$ cations and oxygen vacancies are filled. Thus, the variation of the lattice parameter between pure zirconia and stoichiometric zirconate can be used to estimate the amount of rare earth oxide evaporation.

\subsection{Homogeneity of Chemical and Phase Composition}

The material contrast of backscattered electron images indicates the uneven stoichiometry. The EDS elemental mapping for oxygen, zirconium and lanthanum in the as-sprayed coating obtained at the highest torch input power of $51 \mathrm{~kW}$ confirms that the $\mathrm{La} / \mathrm{Zr}$ ratio varies considerably. The zirconia-rich areas coincide with splat peripheries (Fig. 7). Similar phenomena are expected for GZ coatings, but to a smaller extent since the gadolinia evaporation is less than for LZ. LZ coatings sprayed at 


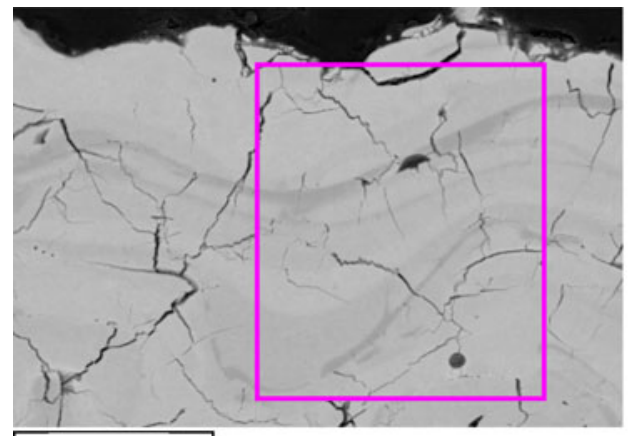

$10 \mu \mathrm{m}$

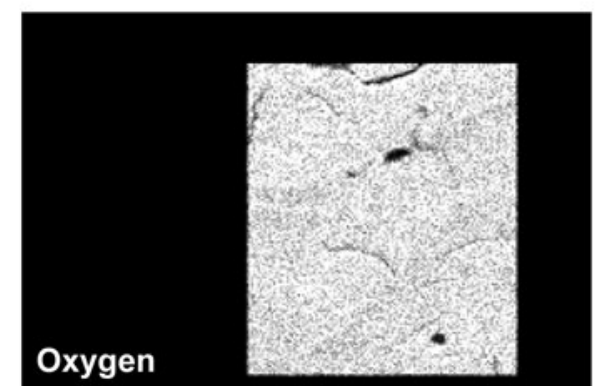

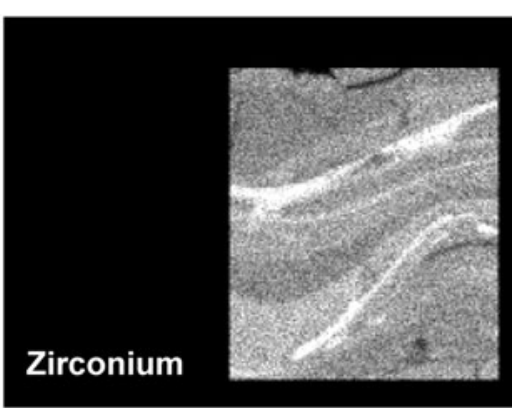

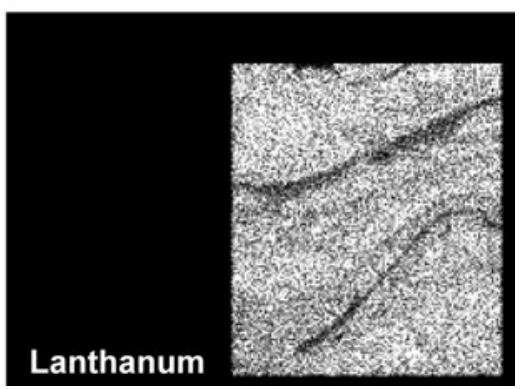

Fig. 7 SEM image (backscattered electrons) and EDS elemental mapping of oxygen, zirconium and lanthanum in the as-sprayed LZ coating at highest applied torch input power of $51 \mathrm{~kW}$

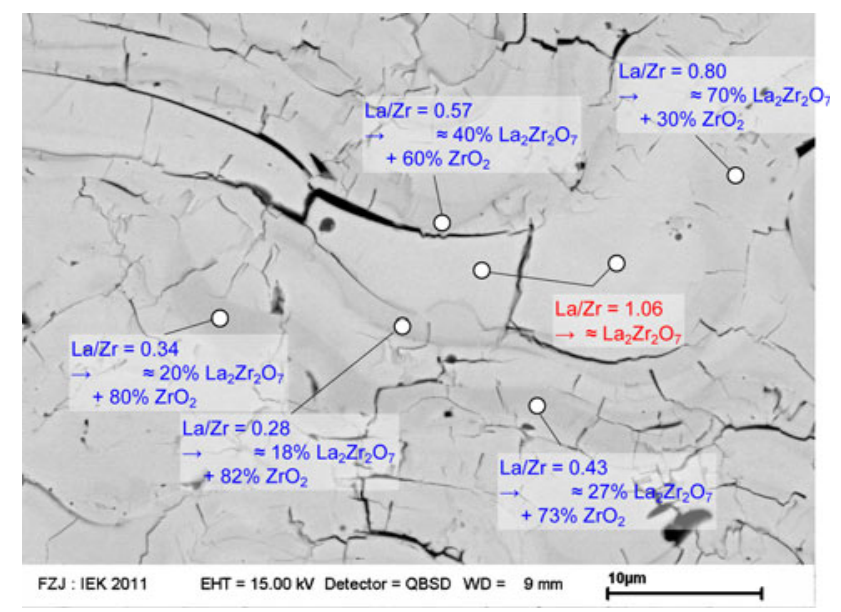

Fig. 8 SEM image (backscattered electrons) and quantitative EDS elemental point analyses of the as-sprayed LZ coating at highest torch input power of $51 \mathrm{~kW}$. The indicated $\mathrm{La} / \mathrm{Zr}$ ratios are atomic ratios, the percentages are $\mathrm{mol} \%$

lower torch input power do not show such pronounced lanthanum-depleted zones. Typically, under such conditions the porosity is larger and some small areas of partially unmelted particles are visible.

Quantitative EDS point analyses of the coatings sprayed at the highest torch power prove that the darker zones represent areas with considerable lanthanum depletion resulting in large amounts of zirconia along with the lanthanum zirconate (Fig. 8). Very low $\mathrm{La} / \mathrm{Zr}$ atomic ratios down to 0.28 were found corresponding to zirconia contents of up to $82 \mathrm{~mol} \%$ with only $18 \mathrm{~mol} \%$ lanthanum zirconate. The zones with intense lanthanum depletion are found at the splat peripheries. This is a clear indication that lanthania is lost by evaporation during flight since its vapor pressure is considerably higher than that of zirconia. Consequently, significant amounts of metastable cubic zirconia can develop. This is confirmed by x-ray diffractograms of annealed coatings sprayed at low and high torch power (Fig. 9). During annealing for $4 \mathrm{~h}$ at $1400^{\circ} \mathrm{C}$, the fluorite transforms to pyrochlore phase and, in particular, the sample sprayed at high torch power develops monoclinic and metastable zirconia phases which will transform and then undergo specific volume changes during thermal cycling. Consequently, the coating will fail very early. One example of a thermally cycled sample is shown in Fig. 10. The surface temperature was $1400{ }^{\circ} \mathrm{C}$, the bondcoat temperature $1040{ }^{\circ} \mathrm{C}$, and the lifetime was only 14 cycles.

\subsection{Monitoring Melting, Evaporation and Solidification During Spray Process}

Most of the particle temperature distributions measured in flight for the lower range of torch input power between 15.0 and $21.9 \mathrm{~kW}$, as well as for higher torch input powers between 24.5 and $35.6 \mathrm{~kW}$, show multimodal shapes, Fig. 11 and 12, respectively. Hence, the distributions are fitted with Gaussian functions to identify different particle fractions. At low power, two peaks can be identified for $\mathrm{LZ}$; one at constant temperature $\left(2570{ }^{\circ} \mathrm{C}\right.$ at 15.0 and $17.3 \mathrm{~kW}$ ) and another one at slightly increasing temperature $\left(2624{ }^{\circ} \mathrm{C}\right.$ at $15.0 \mathrm{~kW}, 2649{ }^{\circ} \mathrm{C}$ at $17.3 \mathrm{~kW}$, $2650{ }^{\circ} \mathrm{C}$ at $19.6 \mathrm{~kW}$, and $2656{ }^{\circ} \mathrm{C}$ at $21.9 \mathrm{~kW}$ ). These peaks disappear at higher torch input power. For GZ, only one 
such peak at almost constant temperature $\left(2556-2584{ }^{\circ} \mathrm{C}\right)$ is observed between 19.6 and $25.4 \mathrm{~kW}$.

Two further peaks appear at variable temperatures for both LZ and GZ. Regarding LZ, one of these peaks oc-
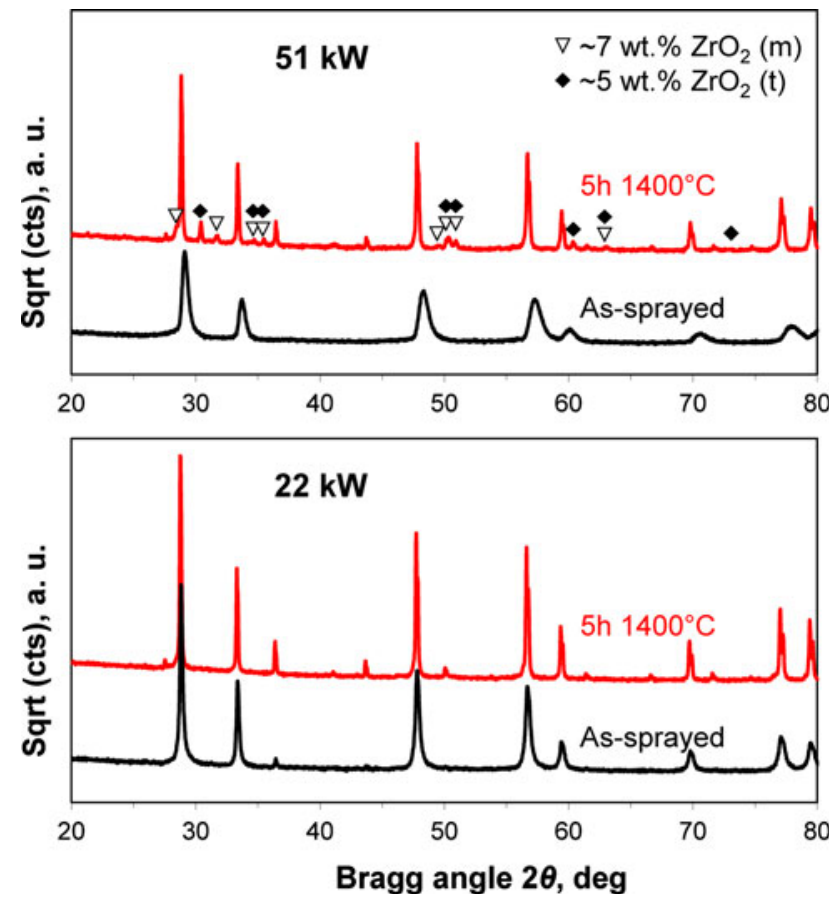

Fig. 9 X-ray diffractograms of annealed coatings sprayed at low and high torch power

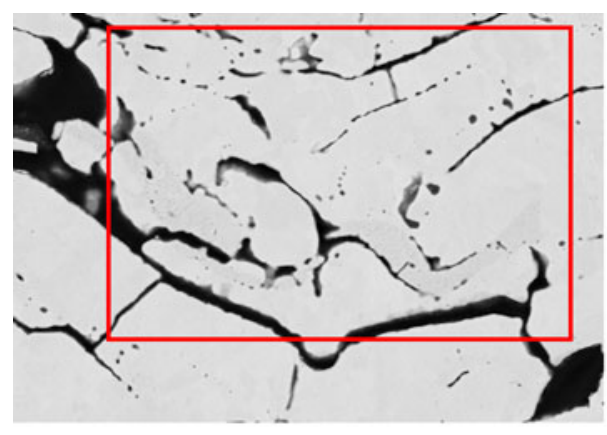

$5 \mu \mathrm{m}$

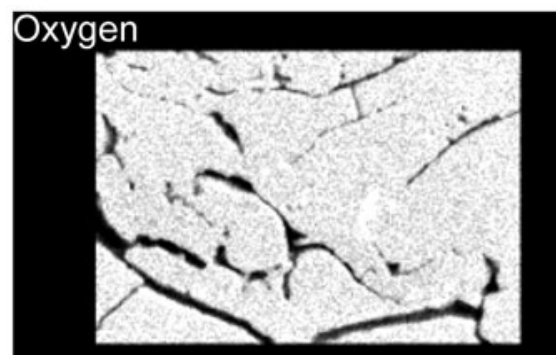

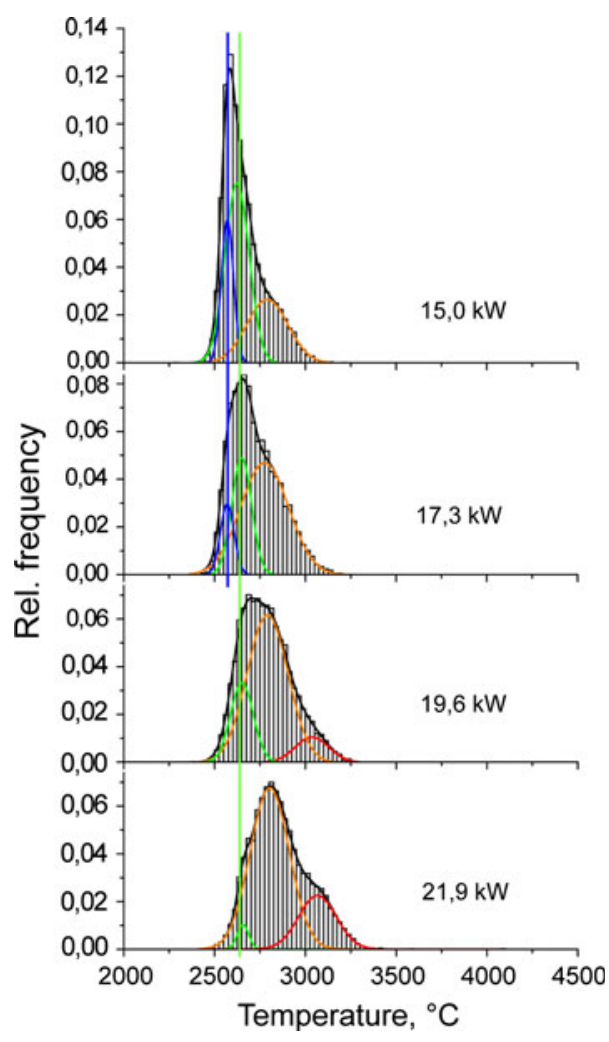

Fig. 11 LZ particle temperature distributions as estimated using two-color pyrometry for the lower range of torch input power between 15.0 and $21.9 \mathrm{~kW}$
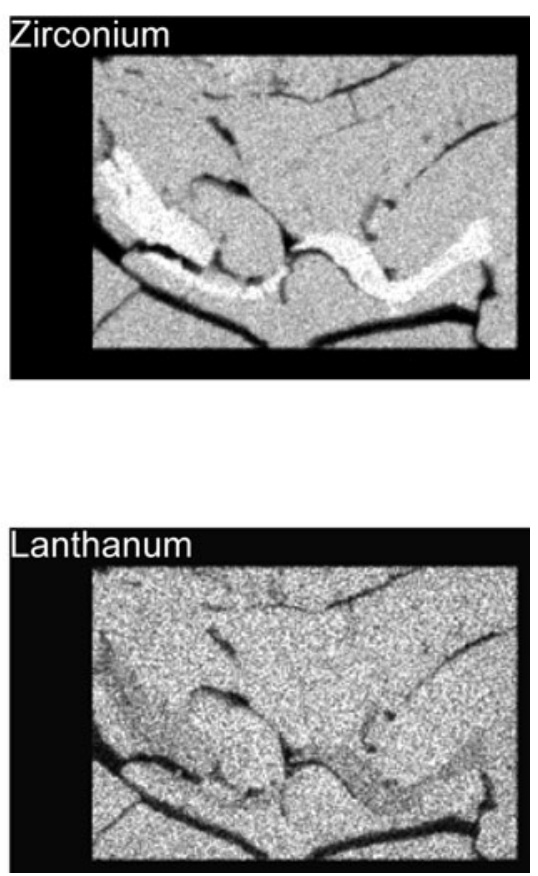

Fig. 10 EDS elemental mapping of thermally cycled coating sprayed at $52 \mathrm{~kW}$ 


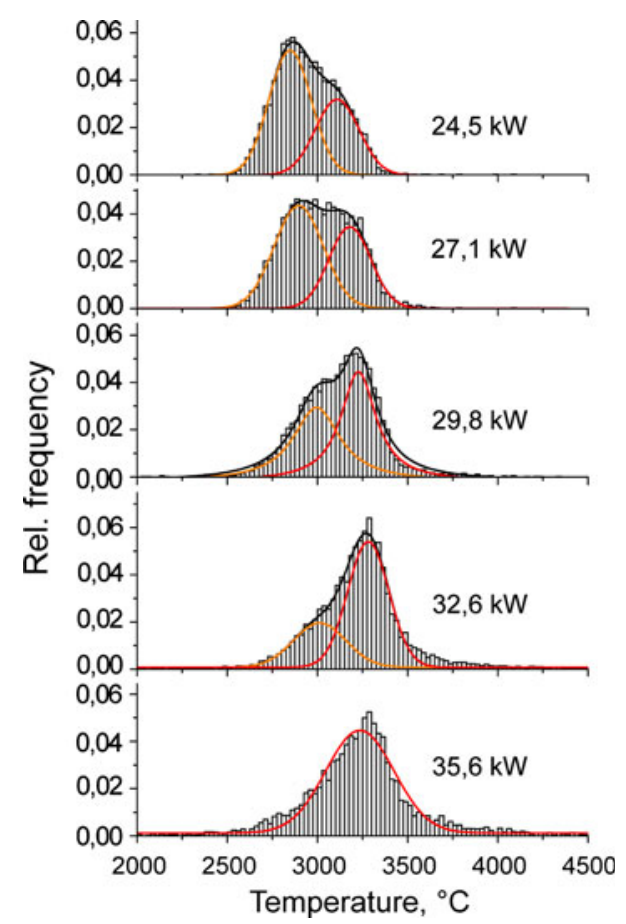

Fig. 12 LZ particle temperature distributions as estimated using two-color pyrometry for higher torch input powers between 24.5 and $36.5 \mathrm{~kW}$ curs from the beginning at $15.0 \mathrm{~kW}$ and vanishes above $32.6 \mathrm{~kW}$, and the other one exists at $19.6 \mathrm{~kW}$ and above. Furthermore, above $32.6 \mathrm{~kW}$ the distributions are increasingly scattered. A similar development is observed using the spherical GZ powder (not shown in this paper), but at a higher power level and with less scattering.

In the lower range of torch input power, the first two LZ peaks at constant and almost constant temperature, respectively, are assumed to be associated with solidification and release of fusion enthalpy. The solidifying behavior of particles in flight is dependent on the lanthania evaporation (Fig. 13). If the lanthania loss is low, solidification occurs immediately above the eutectic line at $2220^{\circ} \mathrm{C}$. Considering the fact that the phase diagram is valid for the equilibrium case only, as well as the limited quantitative accuracy of the two-color pyrometry method applied, this temperature is in reasonable agreement with the measured peak temperature. In the case of more intense lanthania evaporation, the solidification temperature is raised as is reflected by the second peak moving to higher temperatures.

In contrast, the slope of the GZ liquidus line in the phase diagram is small. Thus, the solidification temperature is hardly dependent on the gadolinia content so that only one peak at almost constant temperature is observed in the particle temperature distributions. The mean temperatures of this peak are in good agreement with the theoretical GZ melting temperature of approximately $2600{ }^{\circ} \mathrm{C}$.

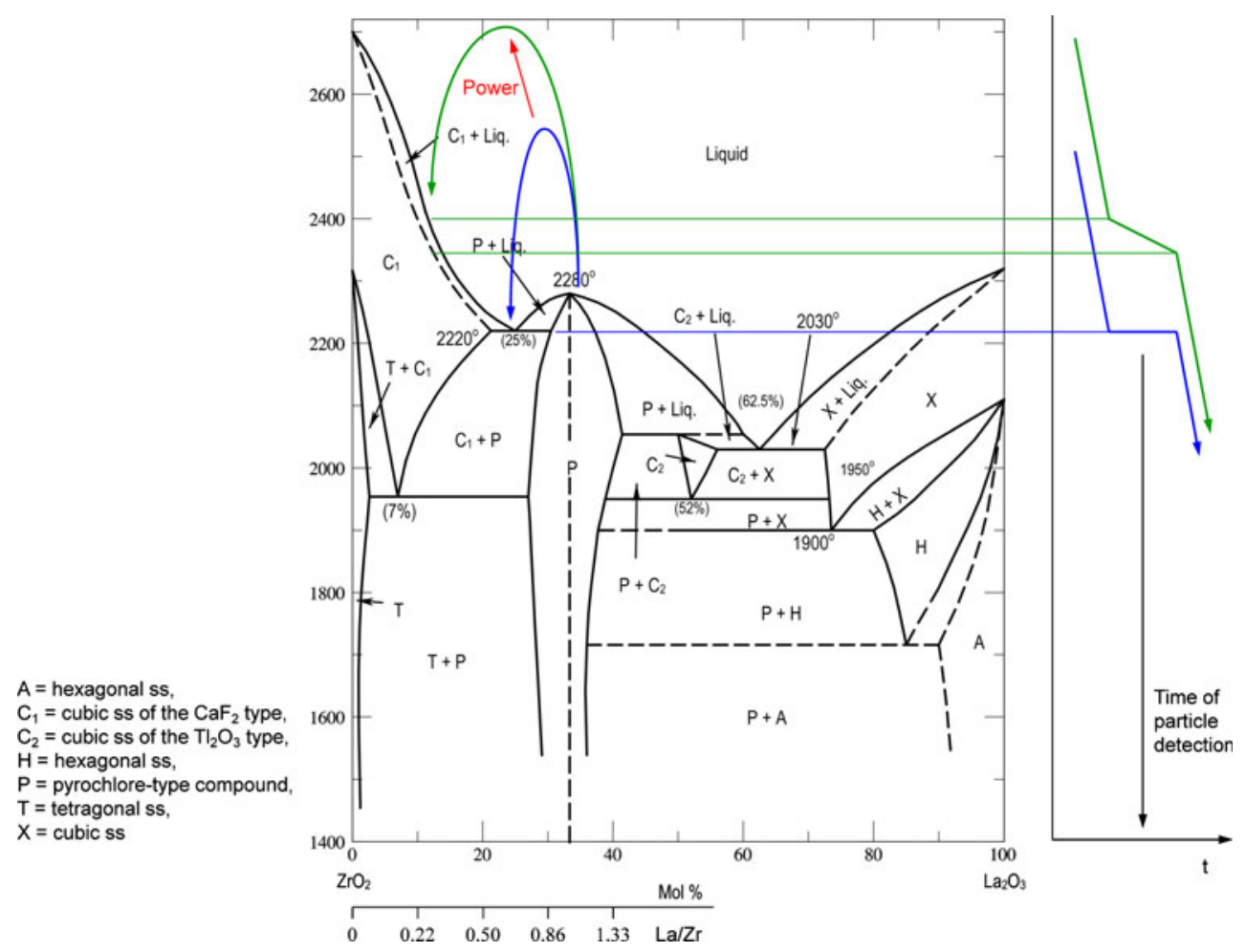

Fig. 13 Solidifying behavior of LZ particles in flight as a function of the lanthania content, phase diagram redrawn after (Ref 17) 


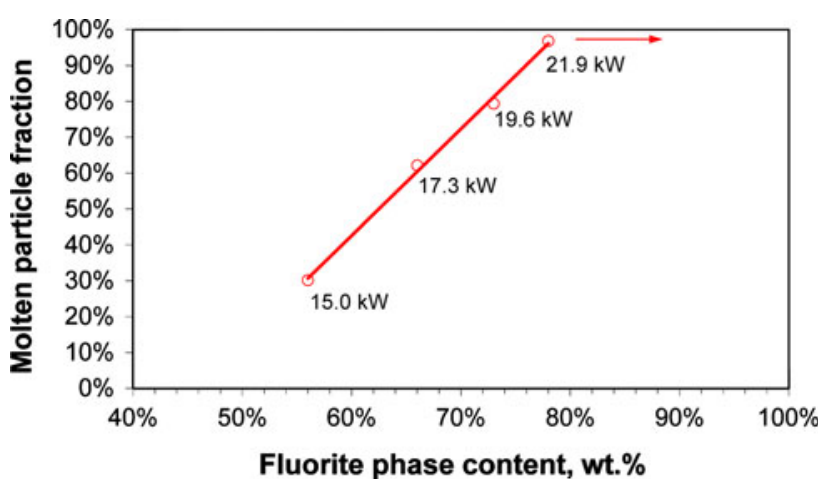

Fig. 14 Correlation of the fluorite contents derived from XRD with the molten LZ particle fractions determined by particle inflight diagnostics

The two other distributions at variable temperatures in both the LZ and GZ cases are associated with molten particles. The reason for the appearance of two distributions is assumed to be the change of the composition at the radiating particle periphery due to the rare earth oxide evaporation. The remaining zirconia is assumed to have different emissivities compared to the zirconates. Thus, the results of two-color pyrometry are affected. Furthermore, if evaporation is intense, the particle radiation is scattered by vapor clouds so that the particle distributions are spread and scattered. This is evident in particular for $\mathrm{LZ}$ at $35.6 \mathrm{~kW}$ and above.

For LZ, the measured in-flight particle temperature distributions were also evaluated quantitatively. For the four lowest power levels applied (15.0-21.9 kW, this corresponds to the power range for which the particles were observed to be partly solidifying in flight), the different particle fractions were determined by calculating the areas under the Gaussian distributions. The amounts of material still molten show a strong linear correlation with the fluorite phase contents revealed by XRD (Fig. 14). Thus, the assumption is confirmed that such LZ material which is still molten upon impingement on the substrate is deposited as fluorite phase while the balance which has already solidified during flight may form pyrochlore.

\section{Conclusion}

Lanthanum zirconate tends to experience the evaporation of lanthania during plasma spraying. Above a specific power level, more lanthania is evaporated at the particle surfaces during flight so that lanthanum-depleted zones occur in the deposited coatings at the splat peripheries. As a consequence, unstabilized zirconia is formed and these non-stoichiometries are expected to be detrimental for applications in thermal barrier coatings. Thus, lanthania evaporation during spraying must be prevented as much as possible.

Based on these results, plasma spray parameters can be identified for the manufacture of stoichiometric lanthanum zirconate thermal barrier coatings so that the advantages of this material may be exploited. Particle diagnostics were found to be an effective tool to detect and monitor lanthania evaporation during the spray process. The composition of the deposited coatings can be analyzed on the basis of lattice parameters obtained by XRD and Rietveld refinement.

\section{Acknowledgments}

The authors would like to gratefully acknowledge helpful discussions with Dr. Maria Ophelia Jarligo as well as the work of Mirko Ziegner (XRD analysis) and of Mark Kappertz (metallographic preparation), all Forschungszentrum Jülich, IEK. They also thank Sabrina Kohnen and Hannelore Lippert, Forschungszentrum Jülich, $\mathrm{ZCH}$, for the chemical analyses.

\section{References}

1. A. Feuerstein, J. Knapp, T. Taylor, A. Ashary, A. Bolcavage, and N. Hitchman, Technical and Economical Aspects of Current Thermal Barrier Coating Systems for Gas Turbine Engines by Thermal Spray and EBPVD: A Review, J. Therm. Spray Tech., 2008, 17(2), p 199-213

2. R. Vaßen, H. Kaßner, A. Stuke, F. Hauler, D. Hathiramani, and D. Stöver, Advanced Thermal Spray Technologies for Applications in Energy Systems, Surf. Coat. Technol., 2008, 202, p 4432-4437

3. S. Stecura, Effects of Compositional Changes on the Performance of a Thermal Barrier Coating System, NASA TM-78976, National Aeronautics and Space Administration, 1978

4. R.A. Miller, J.L. Smialek, and R.G. Garlick, Phase Stability in Plasma-Sprayed, Partially Stabilized Zirconia-Yttria, Advances in Ceramics, Vol 3, Science and Technology of Zirconia, A.H. Heuer and L.W. Hobbs, Ed., The American Ceramic Society, Columbus, OH, 1981, p 241-253

5. D. Zhu and R.A. Miller, Thermal Conductivity and Elastic Modulus Evolution of Thermal Barrier Coatings Under High Heat Flux Conditions, J. Therm. Spray Tech., 2000, 9, p 175-180

6. R. Vaßen, A. Stuke, and D. Stöver, Recent Developments in the Field of Thermal Barrier Coatings, J. Therm. Spray Tech., 2009, 18(2), p 181-186

7. R. Vaßen, X.Q. Cao, F. Tietz, D. Basu, and D. Stöver, Zirconates as New Materials for Thermal Barrier Coatings, J. Am. Ceram. Soc., 2000, 83(8), p 2023-2028

8. D.R. Clarke and S.R. Phillpot, Thermal Barrier Coating Materials, Mater. Today, 2005, 8(6), p 22-29

9. R. Vaßen, M.O. Jarligo, T. Steinke, D.E. Mack, and D. Stöver, Overview on Advanced Thermal Barrier Coatings, Surf. Coat. Technol., 2010, 205, p 938-942

10. X.Q. Cao, R. Vaßen, and D. Stöver, Ceramic Materials for Thermal Barrier Coatings, J. Eur. Ceram. Soc., 2004, 24, p 1-10

11. H. Lehmann, D. Pitzer, G. Pracht, R. Vaßen, and D. Stöver, Thermal Conductivity and Thermal Expansion Coefficients of the Lanthanum Rare-Earth-Element Zirconate System, J. Am. Ceram. Soc., 2003, 86(8), p 1338-1344

12. M.M. Gentleman and D.R. Clarke, Luminescence Sensing of Temperature in Pyrochlore Zirconate Materials for Thermal Barrier Coatings, Surf. Coat. Technol., 2005, 200, p 1264-1269

13. R. Vaßen, F. Traeger, and D. Stöver, New Thermal Barrier Coatings Based on Pyrochlore/YSZ Double-Layer Systems, Int. J. Appl. Ceram. Technol., 2004, 1(4), p 351-361

14. X.Q. Cao, R. Vaßen, F. Tietz, and D. Stöver, New DoubleCeramic-Layer Thermal Barrier Coatings Based on ZirconiaRare Earth Composite Oxides, J. Eur. Ceram. Soc., 2006, 26, p 247-251

15. H. Chen, Y. Liu, Y. Gao, S. Tao, and H. Luo, Design, Preparation, and Characterization of Graded $\mathrm{YSZ} / \mathrm{La}_{2} \mathrm{Zr}_{2} \mathrm{O}_{7}$ Thermal Barrier Coatings, J. Am. Ceram. Soc., 2010, 93(6), p 1732-1740 
16. X.Q. Cao, R. Vaßen, W. Jungen, S. Schwartz, F. Tietz, and D. Stöver, Thermal Stability of Lanthanum Zirconate PlasmaSprayed Coating, J. Am. Ceram. Soc., 2001, 84(9), p 2086-2090

17. A. Rouanet, Contribution a l'étude des systèmes zircone-oxydes des lanthanides au voisinage de la fusion, Revue Internationale des Hautes Températures et des Réfractaires, 1971, 9(2), p 161/80. In: ACerS-NIST Phase Equilibria Diagrams, CD-ROM Database V. 3.1.0, American Ceramic Society, Westerville, OH, USA, 2005

18. A.V. Radha, S.V. Ushakov, and A. Navrotsky, Thermochemistry of Lanthanum Zirconate Pyrochlore, J. Mater. Res., 2009, 24(11), p 3350-3357

19. R. Vaßen, Entwicklung neuer oxidischer Wärmedämmschichten für Anwendungen in stationären und Flug-Gasturbinen, Schriften des Forschungszentrums Jülich, Energy Technology, Vol 33, Forschungszentrum Jülich, 2004 (in German)

20. H. Chen, Y. Gaoa, Y. Liua, and H. Luo, Coprecipitation Synthesis and Thermal Conductivity of $\mathrm{La}_{2} \mathrm{Zr}_{2} \mathrm{O}_{7}$, J. Alloys Compd., 2009, 480, p 843-848

21. H. Chen, Y. Gao, S. Tao, Y. Liu, and H. Luo, Thermophysical Properties of Lanthanum Zirconate Coating Prepared by Plasma
Spraying and the Influence of Post Annealing, J. Alloys Compd., 2009, 486, p 391-399

22. Z. Xu, L. He, R. Mu, S. He, and X. Cao, Preparation and Characterization of $\mathrm{La}_{2} \mathrm{Zr}_{2} \mathrm{O}_{7}$ Coating with the Addition of $\mathrm{Y}_{2} \mathrm{O}_{3}$ by EB-PVD, J. Alloys Compd., 2010, 492, p 701-705

23. J.L. Margrave, Ed., The Characterization of High Temperature Vapors, Wiley, New York, NY, 1967

24. R.J. Meyer, E.H.E. Pietsch, A. Kotowski, M. Becke-Goehring, and K.-C. Buschbeck, Gmelin Handbuch der Anorganischen Chemie, 8th ed., Springer-Verlag, Berlin, 1974 (in German)

25. W. Goldstein, P.N. Walsh, and D. White, Rare Earths. I. Vaporization of $\mathrm{La}_{2} \mathrm{O}_{3}$ and $\mathrm{Nd}_{2} \mathrm{O}_{3}$ : Dissociation Energies of Gaseous LaO and NdO, J. Phys. Chem., 1960, 65, p 1400-1404

26. G. Mauer, R. Vaßen, and D. Stöver, Comparison and Applications of DPV-2000 and Accuraspray-g3 Diagnostic Systems, J. Therm. Spray Tech., 2007, 16, p 414-424

27. H.M. Rietveld, A Profile Refinement Method for Nuclear and Magnetic Structures, J. Appl. Crystallogr., 1969, 2, p 65-71

28. L. Vegard, Die Konstitution der Mischkristalle und die Raumfüllung der Atome, Z. Phys., 1921, 5(1), p 17-26 (in German)

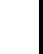

